\title{
Examining Individual- and Community-Level Factors Affecting Skilled Delivery Care among Women Who Received Adequate Antenatal Care in Ethiopia: Using Multilevel Analysis
}

\author{
Eshetu E. Chaka \\ Department of Public Health, College of Medicine and Health Sciences, Ambo University, Ambo, Ethiopia \\ Correspondence should be addressed to Eshetu E. Chaka; eejeta@yahoo.com
}

Received 2 January 2020; Revised 16 September 2020; Accepted 19 September 2020; Published 28 September 2020

Academic Editor: Peng Bao

Copyright (C) 2020 Eshetu E. Chaka. This is an open access article distributed under the Creative Commons Attribution License, which permits unrestricted use, distribution, and reproduction in any medium, provided the original work is properly cited.

\begin{abstract}
Introduction. Maternal mortality continues to be a major public health and development challenge in Africa even after the permissible commitment of the international community. Although the use of skilled delivery care is the key intervention and is effective to lower maternal mortality rates, it is still at a lower proportion. The study is aimed at investigating the individualand community level factors affecting the use of skilled delivery care among those women who had received adequate antenatal care. Materials and Methods. Data were extracted from the 2016 Ethiopian Demographic and Health Survey on women aged 1549 years and gave birth within five years prior to the survey $(N=957)$. Multilevel logistic regression model with two levels were fitted to assess the influence of the individual- and community-level factors on the use of skilled delivery care. Results. Women who were exposed to media were more likely to use skilled delivery care (OR $=1.81 ; 95 \%$ CI: $1.20-2.74)$. Having six or more birth order $(\mathrm{OR}=0.33$; 95\% CI: 0.16-0.69) and residing in rural areas ( $\mathrm{OR}=0.40$; 95\% CI: 0.21-0.79) were associated with less likelihood use of skilled delivery care. Attaining primary and secondary educational level, being older women, being from the richest household, and having a urine test during antenatal visits were significantly associated with the use of skilled delivery care. The value of intraclass correlation coefficient supported a significant community-level effect on the likelihood of using skilled delivery care. Conclusions. Factors operating both at the individual level and community level were found significantly associated with the use of skilled delivery care in Ethiopia. A considerable variation at community level accounts for the difference in the use of skilled delivery level.
\end{abstract}

\section{Introduction}

Maternal mortality continues to be a major public health and development challenge in Africa compared to performance in the rest of the world even after the permissible commitment of the international community during MDG [1]. Increasing access to skilled delivery care during delivery is the key intervention and has proved effective to lower maternal mortality rates globally and in Sub-Saharan Africa [2]. Moreover, the World Health Organization recommends that all women should be attended by a skilled birth attendant during childbirth [3]. However, only 17 percent of pregnant women were attended by a skilled birth attendant in Ethiopia [4]. A skilled health professional can administer interventions to control and manage major life-threatening complica- tions, such as hemorrhage or refer the patient to the next higher level health care facility [3].

Many studies have been done on the utilization and factors associated with skilled delivery care in Ethiopia [5-10]. Nevertheless, these studies were emphasized on individual and household factors and overlooking the contribution of community factors on the utilization of skilled delivery care during delivery. Ignoring the influence of community factors might underestimate the importance of considering them during planning appropriate interventions in scaling up safe motherhood in the country.

Existing literatures showed that the influence of individual- and household-level factors on the use of skilled delivery care vary across geographic and social settings. For example, the women with similar socioeconomic characteristics may 
have different healthcare-seeking behavior depending on whether they live in one community or another so the contextual factors that cluster individuals within communities have become a core notion of social epidemiology [11, 12]. Moreover, a study in Tanzania also showed that poorer households in wealthy regions are found to be better off in maternal health care utilization outcomes than poorer households in poorer regions [13]. Recently, many studies have reported that contextual/community factors are a key determine of maternal health utilization [14-17].

In the case of Ethiopia, there is only one study that tries to consider contextual-level factors associated with skilled delivery care during delivery among women with live birth using the outdated 2011 EDHS [1]. The main research question is why at least those women who had adequate antenatal care (begun first antenatal care within the first trimester, had received at least four antenatal care visits, and had antenatal care from the skilled provider) did not have delivery care by skilled birth providers. This study is aimed at assessing factors associated with the use of skilled delivery care during delivery including unexplored contextual factors in a nationally representative sample using the recent 2016 Ethiopia Demographic and Health Survey (EDHS).

\section{Materials and Methods}

2.1. Data and Study Design. The data for this cross-sectional study were extracted from the 2016 Ethiopia Demographic Health Survey (EDHS), a nationally representative household survey. The survey used a stratified two-stage cluster sampling design. Using the 2007 Ethiopian Population and Housing Census, 645 primary sampling units (PSUs) or clusters were selected using probability proportional at the first stage. In the second stage, a sample of the household was drawn from a listing of households in each of the sampled clusters. The survey included a nationally representative sample of 16,650 households and a total of 7,590 women with live births.

All women aged between 15 and 49 years and residents of Ethiopia were eligible for an interview in the survey. This study was restricted to 957 women who had received adequate antenatal care: four or more antenatal visits, began a first antenatal visit within the first trimester, and had skilled antenatal care and gave birth in the last 5 years preceding the survey. For women who had more than one live birth, only the most recent live birth was considered in this study to get information about the recent birth. Questionnaires were used to collect information in three areas: the household, the women's, and the men's questionnaires.

2.2. Outcome Variables. The outcome variable of this study is the use of skilled delivery care in a health care facility. Skilled delivery care in a health care facility is a binary variable and coded with a value of 1 if doctors, nurses, midwives, or health officers assisted the childbirth and a value of 0 otherwise.

2.3. Exposure Variables. Individual-level factors include the age of mothers at last birth, mother's education level, mother's employment, marital status, household wealth quintile, religion, exposure to media, sex of household, informed about pregnancy complication during pregnancy, blood pressure measured during ANC, a blood sample taken during ANC, urine sample taken during ANC, parity, birth order, and transportation problem to the delivery place. The household wealth index is calculated in the survey using the respondent's household assets by principal component analysis (PCA) and is coded as 1 for "poorest," 2 for "poorer," 3 for "middle," 4 for "richer," and 5 for "richest." Community-level factors include the regional state and type of residence.

2.4. Data Analyses. A descriptive analysis is done for all the individual- and community-level factors to examine their distribution and association with the use of skilled delivery care. Multilevel logistic regression was employed to examine the effect of the individual and community characteristics on the use of skilled delivery care. The usage of the multilevel modeling technique was justified by the hierarchical structure of the survey data, where women are nested within the primary sampling unit or cluster or community. The clustering of observations within the same cluster violates the ordinary logistic regression model independence assumption. Thus, a multilevel modeling strategy accounts for the hierarchical nature of the data and corrects the estimated standard error. A two-level multilevel logistic regression model was performed to test the effect of each independent variable on the use of skilled delivery care in a health facility. Three sequential models were fitted. Firstly, model- 0 or the intercept-only model was fitted without explanatory variables. Secondly, model-1 was fitted with only individual and household variables. Thirdly, model-2 was fitted with only community-level variables. Lastly, model-3 was fitted with a community-level variable in addition to individual and household variables. The multilevel binary logistic regression model equation is written as follows:

$$
\operatorname{Logit}\left(P_{i j}\right)=\beta 0+\beta_{1} I+\beta_{2} C+u_{j}
$$

where $P_{i j}$ is the probability of skilled delivery care for women $i$ nested in the cluster $j$, the $\beta$ 's are the fixed coefficients, $I$ and $C$ refer to the individual- and community-level-independent variables, respectively, and $u_{j}$ indicate the random effects for the $j^{\text {th }}$ cluster.

Measures of association (fixed effects) are measured using the odds ratio (OR) along with 95\% confidence intervals (CI).

A measure of variation (random effects) is measured using the variance partition coefficient (VPC) and proportional change in variance $(\mathrm{PCV})$. The variance partition coefficient or the variance coefficient (ICC) was assessed as shown:

$$
\mathrm{ICC}=\frac{\sigma u^{2}}{\sigma u^{2}+\pi 2 / 3}
$$

where $\pi 2 / 3$ denotes the variance between mothers in the same cluster (individual level) and $\sigma^{2} u$ is the variance 
between clusters (community-level variance). It measures the extent of the variance explained at the community level [18]. The entire analysis was done using STATA version 14 .

\section{Results}

3.1. Description of Skilled Delivery Care Use by Background Characteristics. Table 1 presents the percentage distribution of the use of skilled delivery care by the participant's background characteristics. The percentage of skilled delivery care use was fairly equivalent across maternal age at last birth, 66\% was aged 15-24 years, 67\% was aged 25-34 years, and $57 \%$ was aged 35-49 years. The utilization of skilled delivery care was higher among the women who have attended primary and secondary or higher school as compared to those with no formal education.

Women who reside in urban areas, formally employed, from the richest household, reported Orthodox Christian affiliation, had first birth order, exposed to mass media, and had been informed about pregnancy complications during antenatal care visit were the advantaged group to use skilled delivery care. Moreover, those women who had blood pressure measured, had a blood sample tested, and had a urine test during antenatal care visits were more likely to use skilled delivery care as compared to their counterparts.

3.2. Multivariable Multilevel Logistic Analysis. Table 2 presents the result of multivariable multilevel binary logistic regression analysis. Older women were significantly more likely to use skilled delivery care than women age 15-24 years in model-3, the best-fitted model as it has the lowest Akaike Information Criterion statistics. Mother's educational level is found to have a significant association with skilled delivery care. Women who attended primary and secondary or higher education were significantly more likely to use skilled delivery care than women not have an education. Among household wealth quintile, only those women from the richest household were found to have a significant association with skilled birth delivery care. Living in the richest household increases the odds of skilled delivery care use than living in the poorest household. Women with six or more birth order were $66 \%$ less likely to use skilled delivery care in a health facility than women with the first birth order. Women who are exposed to radio or television or newspaper at least once per week have a higher likelihood of using skilled delivery care than those women not exposed to the media.

The odds of using skilled delivery care was higher among women who perceived that distance to a health facility to get health care is not a big problem compared to those who perceived it as a big problem.

As shown in model- 3 of Table 2 community-level variables have a significant association with the use of skilled delivery care. Women who reside in rural areas were $60 \%$ less likely to use skilled delivery care compared to those residing in urban areas.

3.3. Random Effect Parameter and Model Fitness Statistics. Table 3 shows the intracluster correlation and model fit statistics. The findings in model- 0 show that $53 \%$ of the total variance in the use of skilled delivery care is attributable to the community-level differences. The use of skilled delivery care is clustered significantly by the community. The intracluster correlation coefficients for the use of skilled delivery care reduced by more than half when individuallevel variables were added into model-1. When the model was fitted with only community-level variables, $19.1 \%$ of the community-level variance in the use of skilled delivery care across clusters was explained.

However, when the community-level factors and individual-level factors were entered in model-3 simultaneously, the estimate of the intracluster correlation for the use of skilled delivery care shows nearly no change when compared with model-1. Although the percentage of the intracluster correlations reduced substantially, there is still a statistically significant community-level variance across each model that remains unexplained. This finding indicates that there are unobserved variables not included in this study that is related to the clustering in the use of skilled delivery care.

\section{Discussion}

The finding showed that near to two-thirds of women 617 (64.5\%; 95\% CI: 61.5-67.5) use the skilled delivery care in health facilities among women who had received adequate antenatal care in Ethiopia.

In model-3 in which individual- and community level factors were entered simultaneously, there is a significant association between maternal age at last birth and the use of skilled delivery care.

The finding revealed that the odds of using skilled delivery care are higher among older mothers compared to younger mothers. This might due to that older woman have a better awareness of availability and accessibility of health care services, and they have maternal health services experience than younger women. For instance, women in the age group $35-49$ at last birth were twice $(\mathrm{OR}=2.07 ; 95 \% \mathrm{CI}: 1.07,4.03)$ more likely to use skilled delivery care than those in the age group 15-24. This finding is supported by the results of the previous studies elsewhere. For example, older women were more likely to use delivery care and studies argued that older age women have better maternal health care experience and awareness of the availability of maternal health care service $[1,10,16,19]$.

The odds of using skilled delivery care decreased consistently as the order of birth increases among women who had received adequate antenatal care. That means women with higher birth orders are less likely to use skilled delivery care either because of having fewer resources due to large family size or their maternal health care experiences as mentioned in the previous study $[10,16,20]$.

Women's educational attainment was significantly associated with the use of skilled delivery care. Women who had attained primary and secondary or above educational levels had higher odds of using skilled delivery care than those with no education. Moreover, the likelihood of using skilled delivery cares increased positively with the educational level of women. This result was consistent with the previous studies [21-24]. The previous studies explained that 
TABLE 1: Distribution of skilled delivery care in a health facility by background characteristics.

\begin{tabular}{|c|c|c|c|}
\hline Background characteristics & Yes $(\%)$ & No $(\%)$ & $P$ value \\
\hline Maternal age at last birth & 957 & & 0.2062 \\
\hline $15-24$ & 65.7 & 34.3 & \\
\hline $25-34$ & 66.8 & 33.2 & \\
\hline $35-49$ & 56.7 & 43.3 & \\
\hline Current marital status & & & 0.6386 \\
\hline Never/widowed/divorced/separated & 67.7 & 33.3 & \\
\hline Currently married or living together & 64.2 & 35.8 & \\
\hline Mother's employment & & & 0.0001 \\
\hline Unemployed & 60.1 & 39.9 & \\
\hline Formal employment & 88.3 & 11.7 & \\
\hline Agricultural employment & 59.2 & 40.8 & \\
\hline Unskilled manual workers & 69.1 & 30.9 & \\
\hline Type of place of residence & & & 0.0001 \\
\hline Urban & 91.8 & 8.2 & \\
\hline Rural & 48.6 & 51.4 & \\
\hline Mother's educational attainment & & & 0.0001 \\
\hline No education & 44.2 & 55.8 & \\
\hline Primary & 67.3 & 32.7 & \\
\hline Secondary or higher & 92.4 & 7.6 & \\
\hline Household wealth index & & & 0.0001 \\
\hline Poorest & 41.2 & 58.8 & \\
\hline Poor & 43.7 & 56.3 & \\
\hline Middle & 47.8 & 52.2 & \\
\hline Rich & 50.7 & 49.3 & \\
\hline Richest & 91.8 & 8.2 & \\
\hline Region & & & 0.0001 \\
\hline Oromia & 58.6 & 41.4 & \\
\hline SNNP & 54.7 & 45.3 & \\
\hline Amhara & 53.1 & 46.9 & \\
\hline Addis Ababa \& Dire Dawa & 94.5 & 5.5 & \\
\hline Tigray & 79.2 & 20.8 & \\
\hline Others & 63.5 & 36.5 & \\
\hline Religion & & & 0.009 \\
\hline Orthodox & 70.3 & 29.7 & \\
\hline Protestant \& others & 52.2 & 47.8 & \\
\hline Muslim & 57.2 & 42.8 & \\
\hline Parity (number of children) & & & 0.0001 \\
\hline $1=$ at most one & 75.2 & 24.8 & \\
\hline 2 & 74.9 & 25.1 & \\
\hline $3-4$ & 55.1 & 44.9 & \\
\hline 5 or more & 44.2 & 55.8 & \\
\hline Birth order & & & 0.0001 \\
\hline First & 77.4 & 22.6 & \\
\hline $2-3$ & 68.67 & 31.3 & \\
\hline $4-5$ & 54.4 & 45.6 & \\
\hline $6+$ & 36.7 & 63.3 & \\
\hline
\end{tabular}


TABLE 1: Continued.

\begin{tabular}{|c|c|c|c|}
\hline Background characteristics & Yes $(\%)$ & No $(\%)$ & $P$ value \\
\hline Wanted pregnancy when became pregnant & & & 0.9213 \\
\hline Yes, then & 65.0 & 35.0 & \\
\hline Yes, later & 62.8 & 37.2 & \\
\hline No more & 62.3 & 37.5 & \\
\hline Told about pregnancy complications & & & 0.0013 \\
\hline No & 56.2 & 43.8 & \\
\hline Yes & 70.6 & 29.4 & \\
\hline Exposed to media & & & 0.0001 \\
\hline No & 43.4 & 56.6 & \\
\hline Yes & 80.7 & 19.3 & \\
\hline Sex of household head & & & 0.0006 \\
\hline Male & 60.8 & 39.2 & \\
\hline Female & 80.0 & 20.0 & \\
\hline Getting money needed for self-treatment & & & 0.0001 \\
\hline A big problem & 52.6 & 47.4 & \\
\hline Not a big problem & 73.6 & 26.4 & \\
\hline Distance to a health facility to get medical help & & & 0.0001 \\
\hline A big problem & 50.3 & 49.7 & \\
\hline Not a big problem & 73.7 & 26.3 & \\
\hline Getting permission to go to a health facility & & & 0.0011 \\
\hline A big problem & 50.4 & 49.6 & \\
\hline Not a big problem & 69.0 & 31.0 & \\
\hline Blood pressure checked at least once during ANC & & & 0.0003 \\
\hline No & 41.0 & 59.0 & \\
\hline Yes & 67.5 & 32.5 & \\
\hline A urine test conducted during ANC & & & 0.0001 \\
\hline No & 34.0 & 66.0 & \\
\hline Yes & 68.0 & 32.0 & \\
\hline A blood test conducted during ANC & & & 0.0001 \\
\hline No & 33.4 & 66.6 & \\
\hline Yes & 68.2 & 31.8 & \\
\hline Received at least one tetanus injection during ANC & & & 0.4333 \\
\hline No & 60.4 & 39.6 & \\
\hline Yes & 65.5 & 34.5 & \\
\hline
\end{tabular}

educated mothers have better access to health problem information, a high level of health literacy, awareness to overcome cultural barriers, and good power of decision making. Attending a higher education level empowers women to control health care and to encourage to access quality maternal health care.

The likelihood of using skilled delivery care was higher among women from the richest household than those from the poorest household. This finding is in line with other studies elsewhere $[19,25]$.

Moreover, the study also found that access/exposure to media had a significant association with the use of skilled delivery care. Having exposure to media influences the knowledge of women about health care needs during delivery and the availability and accessibility of such services $[1,24]$.
The study result showed a significant association between women's residence and the use of skilled delivery care. For example, women residing in rural areas were less likely to use skilled delivery care as compared with those residing in urban areas. This finding is consistent with studies done elsewhere. Scattered nature of the rural area, limited supply of health facilities, a far distance from health facilities, and difficulty accessing information and media in rural areas are some of the reasons mentioned [1, 16, 24]. However, a region, where women reside, was not found significantly associated with the use of skilled delivery.

\section{Conclusions}

At the individual level, being in an older age group, residing in the richest household, attaining a primary and secondary 
TABLE 2: Multivariable multilevel logistic regression analysis of individual-level and community-level factors associated with the use of skilled delivery care.

\begin{tabular}{|c|c|c|c|c|}
\hline Background characteristics & Model0 & Model-1 & Model-2 & Model-3 \\
\hline \multicolumn{5}{|l|}{ Maternal age at last birth } \\
\hline $15-24$ & & 1.0 & - & 1.0 \\
\hline $25-34$ & & $1.22(0.75,1.96)$ & - & $1.22(0.75,1.96)$ \\
\hline $35-49$ & & $2.14(1.10,4.17)^{*}$ & - & $2.07(1.07,4.03)^{*}$ \\
\hline \multicolumn{5}{|c|}{ Mother's educational attainment } \\
\hline No education & & 1.0 & - & 1.0 \\
\hline Primary & & $1.69(1.12,2.57)^{*}$ & - & $1.71(1.13,2.59)^{*}$ \\
\hline Secondary or higher & & $4.25(2.32,7.77)^{* *}$ & - & $4.08(2.23,7.45)^{* * *}$ \\
\hline \multicolumn{5}{|l|}{ Household wealth index } \\
\hline Poorest & & 1.0 & - & 1.0 \\
\hline Poor & & $1.32(0.74,2.37)$ & - & $1.34(0.75,2.39)$ \\
\hline Middle & & $1.41(0.76,2.58)$ & - & $1.40(0.77,2.55)$ \\
\hline Rich & & $1.03(0.55,1.91)$ & - & $0.99(0.54,1.84)$ \\
\hline Richest & & $5.27(2.82,9.83)^{* *}$ & - & $2.60(1.22,5.56)^{*}$ \\
\hline \multicolumn{5}{|l|}{ Birth order } \\
\hline First & & 1.0 & - & 1.0 \\
\hline $2-3$ & & $0.80(0.49,1.31)$ & - & $0.79(0.48,1.29)$ \\
\hline $4-5$ & & $0.68(0.37,1.27)$ & - & $0.66(0.35,1.21)$ \\
\hline $6+$ & & $0.35(0.17,0.74)^{* *}$ & - & $0.33(0.16,0.69)^{* *}$ \\
\hline \multicolumn{5}{|l|}{ Exposed to media } \\
\hline No & & 1.0 & - & 1.0 \\
\hline Yes & & $1.83(1.21,2.78)^{* *}$ & - & $1.81(1.20,2.74)^{*}$ \\
\hline \multicolumn{5}{|l|}{ Getting money } \\
\hline A big problem & & 1.0 & - & - \\
\hline Not a big problem & & $1.46(1.00,2.12)^{*}$ & - & - \\
\hline \multicolumn{5}{|c|}{ Blood pressure checked at least once during ANC } \\
\hline No & & 1.0 & - & 1.0 \\
\hline Yes & & $1.64(0.90,2.98)$ & - & $1.61(0.88,2.92)$ \\
\hline \multicolumn{5}{|c|}{ A urine test conducted during an antenatal visit } \\
\hline No & & 1.0 & - & 1.0 \\
\hline Yes & & $2.14(1.15,3.99)^{*}$ & - & $2.03(1.09,3.77)^{*}$ \\
\hline \multicolumn{5}{|c|}{ Distance to a health facility to get medical help } \\
\hline A big problem & & 1.0 & - & - \\
\hline Not a big problem & & $1.59(1.10,2.32)^{*}$ & - & - \\
\hline \multicolumn{5}{|l|}{ Type of place of residence } \\
\hline Urban & & - & 1.0 & 1.0 \\
\hline Rural & & - & $0.03(0.011,0.07)$ & $0.40(0.21,0.79)^{* *}$ \\
\hline Region & & - & & \\
\hline Oromia & & - & 1.0 & 1.0 \\
\hline SNNP & & - & $1.10(0.44,2.67)$ & $1.20(0.48,1.45)$ \\
\hline Amhara & & - & $0.77(0.33,1.81)$ & $0.70(0.43,1.85)$ \\
\hline AA \& DW & & - & $3.64(0.94,14.10)$ & $2.04(0.90,9.00)$ \\
\hline Tigray & & - & $5.40(2.06,14.14)^{*}$ & $3.21(0.13,8.10)^{*}$ \\
\hline Others & & - & $0.78(0.24,2.51)$ & $0.77(0.24,2.51)$ \\
\hline
\end{tabular}


TABLE 3: Random effect parameters and model fit statistics in the use of skilled delivery care in a health facility, Ethiopia.

\begin{tabular}{|c|c|c|c|c|}
\hline Random effects & Model-0 & Model-1 & Model-2 & Model-3 \\
\hline Community level variance (SE) & $3.756(0.846)^{* * *}$ & $0.971(0.356)^{* *}$ & $3.04(0.673)^{* *}$ & $0.933(0.341)^{* *}$ \\
\hline ICC (VPC) (\%) & 53.3 & 22.7 & 48.0 & 22.1 \\
\hline Explained variance or PCV (\%) & Reference & 74.0 & 19.1 & 75.2 \\
\hline \multicolumn{5}{|l|}{ Model fit statistics } \\
\hline Deviance & 1318.86 & 1050.80 & 1070.14 & 1043.18 \\
\hline AIC & 1322.86 & 1086.81 & 1086.14 & 1079.19 \\
\hline $\mathrm{BIC}$ & 1333.07 & 1178.71 & 1127.71 & 1171.09 \\
\hline
\end{tabular}

SE: standard error: ICC: intracluster correlation; VPC: variance partition coefficient; PCV: proportional change in variance.

education level, having exposure to the media, and had a urine test during antenatal care were significantly associated with the use of skilled delivery care. Moreover, having six or more birth order was inversely associated with skilled delivery care. At the community level, residing in rural areas was significantly associated with the use of skilled delivery. Factors affecting the use of skilled delivery care operated both at the individual and community levels. The study demonstrated that there is a significant variation in the use of skilled delivery care across the community. Thus, any interventions intended to increase the use of skilled delivery care should consider community-level factors at large. This study also indicated the need to contextualize the strategies and explore the factors responsible for the unexplained variance in the use of skilled delivery care.

\section{Data Availability}

The data used to support the findings of this study are available from the Measure DHS project upon request.

\section{Conflicts of Interest}

The authors declare no conflict of interest.

\section{Authors' Contributions}

EEC had substantial contributions to the conception or design of the manuscript and drafting the manuscript or revising it critically for important intellectual content. ECC did the final reading and gave approval of the final version to be published.

\section{Acknowledgments}

The authors thank all the study participants, interviewers and finally Measure DHS project for providing the data sets for this analysis. This work supported by the Tehran University of Medical Sciences international campus.

\section{References}

[1] M. Mezmur, K. Navaneetham, G. Letamo, and H. Bariagaber, "Individual, household and contextual factors associated with skilled delivery care in Ethiopia: evidence from Ethiopian demographic and health surveys," PLoS One, vol. 12, no. 9, article e0184688, 2017.

[2] N. Prata, A. Sreenivas, F. Greig, J. Walsh, and M. Potts, "Setting priorities for safe motherhood interventions in resourcescarce settings," Health Policy, vol. 94, no. 1, pp. 1-13, 2010.

[3] M. P. Safer, Making Pregnancy Safer: The Critical Role of the Skilled Attendant, World Health Organization, Geneva, 2004.

[4] Central Statistical Agency (CSA) [Ethiopia] and ICF, Ethiopia Demographic and Health Survey 2016, CSA and ICF, Addis Ababa, Ethiopia, and Rockville, MD, USA, 2016.

[5] Z. B. Mengesha, G. A. Biks, T. A. Ayele, G. A. Tessema, and D. N. Koye, "Determinants of skilled attendance for delivery in Northwest Ethiopia: a community based nested case control study," BMC Public Health, vol. 13, no. 1, p. 130, 2013.

[6] M. Nigussie, D. H. Mariam, and G. Mitike, "Assessment of safe delivery service utilization among women of childbearing age in north Gondar Zone, North West Ethiopia," Ethiopian Journal of Health Development, vol. 18, pp. 145-152, 2004.

[7] N. K. Beam, G. Bekele Dadi, S. H. Rankin, S. Weiss, B. Cooper, and L. M. Thompson, "A discrete choice experiment to determine facility-based delivery services desired by women and men in rural Ethiopia," BMJ Open, vol. 8, no. 4, article e016853, 2018.

[8] K. Birmeta, Y. Dibaba, and D. Woldeyohannes, "Determinants of maternal health care utilization in Holeta town, central Ethiopia," BMC Health Services Research, vol. 13, no. 1, p. 256, 2013.

[9] G. Abeje, M. Azage, and T. Setegn, "Factors associated with Institutional delivery service utilization among mothers in Bahir Dar City administration, Amhara region: a community based cross sectional study," Reproductive Health, vol. 11, no. 1, p. 22, 2014.

[10] M. Fekadu and N. Regassa, "Skilled delivery care service utilization in Ethiopia: analysis of rural-urban differentials based on national demographic and health survey (DHS) data," African Health Sciences, vol. 14, no. 4, pp. 974-984, 2014.

[11] J. Merlo, M. Yang, B. Chaix, J. Lynch, and L. Råstam, “A brief conceptual tutorial on multilevel analysis in social epidemiology: investigating contextual phenomena in different groups of people," Journal of Epidemiology \& Community Health, vol. 59, no. 9, pp. 729-736, 2005.

[12] R. Andersen and J. F. Newman, "Societal and individual determinants of medical care utilization in the United States," The Milbank Memorial Fund Quarterly. Health and Society, vol. 51, no. 1, pp. 95-124, 1973. 
[13] M. E. Kruk, P. C. Rockers, G. Mbaruku, M. M. Paczkowski, and S. Galea, "Community and health system factors associated with facility delivery in rural Tanzania: a multilevel analysis," Health Policy, vol. 97, no. 2-3, pp. 209-216, 2010.

[14] R. Stephenson, A. Baschieri, S. Clements, M. Hennink, and N. Madise, "Contextual influences on the use of health facilities for childbirth in Africa," American Journal of Public Health, vol. 96, no. 1, pp. 84-93, 2006.

[15] A. Sepehri, S. Sarma, W. Simpson, and S. Moshiri, "How important are individual, household and commune characteristics in explaining utilization of maternal health services in Vietnam?," Social Science \& Medicine, vol. 67, no. 6, pp. 1009-1017, 2008.

[16] S. O. Babalola, "Factors associated with use of maternal health services in Haiti: a multilevel analysis," Revista Panamericana de Salud Pública, vol. 36, no. 1, pp. 1-9, 2014.

[17] O. Aremu, S. Lawoko, and K. Dalal, "The influence of individual and contextual socioeconomic status on obstetric care utilization in the Democratic Republic of Congo: a populationbased Study," International Journal of Preventive Medicine, vol. 3, no. 4, pp. 278-285, 2012.

[18] H. Goldstein, W. Browne, and J. Rasbash, "Partitioning variation in multilevel models," Understanding Statistics, vol. 1, no. 4, pp. 223-231, 2002.

[19] D. N. Ononokpono and C. O. Odimegwu, "Determinants of maternal health care utilization in Nigeria: a multilevel approach," The Pan African Medical Journal, vol. 17, Supplement 1, 2014.

[20] S. Gabrysch and O. M. Campbell, "Still too far to walk: literature review of the determinants of delivery service use," $B M C$ Pregnancy and Childbirth, vol. 9, no. 1, p. 34, 2009.

[21] M. Alemayehu and W. Mekonnen, "The prevalence of skilled birth attendant utilization and its correlates in North West Ethiopia," BioMed Research International, vol. 2015, Article ID 436938, 8 pages, 2015.

[22] B. Choulagai, S. Onta, N. Subedi et al., "Barriers to using skilled birth attendants' services in mid- and far-western Nepal: a cross-sectional study," BMC International Health and Human Rights, vol. 13, no. 1, p. 49, 2013.

[23] S. Yanagisawa, S. Oum, and S. Wakai, "Determinants of skilled birth attendance in rural Cambodia," Tropical Medicine \& International Health, vol. 11, no. 2, pp. 238-251, 2006.

[24] M. L. Sagna and T. S. Sunil, "Effects of individual and neighborhood factors on maternal care in Cambodia," Health \& Place, vol. 18, no. 2, pp. 415-423, 2012.

[25] M. Islam and J. Odland, "Determinants of antenatal and postnatal care visits among indigenous people in Bangladesh: a study of the Mru community," Rural \& Remote Health, vol. 11, 2011. 